Гайфуллин Рамиль Гусманович

аспирант кафедры экономики и таможенного дела, Поволжского института управления Академии народного хозяйства и государственной службы при Президенте Российской Федерации

\section{РОЛЬ И МЕСТО СИСТЕМЫ ОХРАНЫ ТРУДА В СОЦИАЛЬНО- ЭКОНОМИЧЕСКОМ РАЗВИТИИ}

Аннотация:

Статья посвящена изучению роли и места охраны труда в социально-экономическом развитии. Целью ее является поиск взачмосвязей между понятиями «система охраны труда» $u$ «социально-экономическое развитие». Предметом научного исследования была избрана система охраны труда. В работе мы использовали следующие методы научного исследования: анализ, синтез, изучение научных трудов по выявленной проблеме и обобщение изученной информации. Научная новизна исследования состоит в определении понятия человеческого капитала как одного из связующих элементов между охраной труда и социально-экономическим развитием на базе обобщения исследований по данной проблеме, изучения социальных и экономических аспектов системы охраны труда. В ходе проведенного исследования было доказано, что ценность человека и его безопасность яөляются определяющими показателями системы охраны труда, а сама система действенным инструментом, который позволяет обеспечивать социально-экономическую эффективность и непрерывное развитие предприятия, региона и страны в целом. Полученные результаты могут служить основой для последующих научных исследований. Выявленные ключевые взаимосвязи целесообразно взять за основу при создании планов модернизации системы охраны труда на предприятиях.

Ключевые слова:

охрана труда, условия труда, экономический рост, социально-экономическое развитие, условия труда, человеческий капитал.

\section{Gaifullin Ramil Gusmanovich}

PhD student, Economics and Customs Department, Povolzhsky Institute of Management, Russian Presidential Academy of National Economy and Public Administration

\section{THE ROLE AND PLACE OF THE LABOR PROTECTION SYSTEM IN SOCIO-ECONOMIC DEVELOPMENT}

Summary:

The paper dwells upon the role and place of labor protection in socio-economic development. The goal is to find the connections between the notions of "labor protection system" and "socio-economic development". The subject of the scientific research is the labor protection system. The work contains the following methods of scientific research: analysis, synthesis, the study of scientific papers on the identified problem and the generalization of the information studied. The scientific novelty of the research consists in defining the concept of human capital as one of the connecting elements between labor protection and socio-economic development on the basis of the generalization of the researches on this issue, the study of social and economic aspects of the labor protection system. In the course of the scientific work, it was proved that the value of a person and his safety are the defining indicators of the labor protection system. The system itself is an effective tool that allows one to achieve socio-economic efficiency and development of an enterprise, region and country as a whole. The results obtained in the work can serve as the basis for subsequent researches. The identified key relationships can be taken as the basis for creating plans for the modernization of the labor protection system at enterprises.

Keywords: labor protection, working conditions, economic growth, socio-economic development, human capital.

На сегодняшний день социально-экономическое развитие невозможно без улучшения условий труда и благосостояния населения. Прорыв в экономическом развитии становится реальным при грамотном поиске и применении новых технологий, улучшении производительности и капиталоемкости производств. Ключевым механизмом для обеспечения вышеупомянутых целей служит система охраны труда. С развитием современных технологий и появлением новых видов производств требуется принципиально новый подход к ее функционированию. Предполагается, что совершенствование системы охраны труда должно осуществляться совместно с организацией новых производственных структур для достижения социально-экономического развития.

Стоит отметить, что в научной плоскости данному вопросу уделяется мало внимания. О проблеме отсталости российской системы охраны труда на местах и причинах такого положения дел пишет в своей работе С.Г. Брусенцов [1]. Г.Н. Тугускина [2] определяет ключевое направление в социально-экономическом развитии - человеческий капитал, который сохраняется и совершенствуется в прямой зависимости от уровня функционирования системы охраны труда.

Нами были изучены взгляды на имеющуюся в России систему охраны труда ряда ученых, среди которых: Н.В. Косинова, О.К. Комаров, Л.В. Серегина, С.О. Кузьмина и др. [3]. Заслуга упомянутых авторов состоит в том, что каждый из них рассматривал многогранную систему охраны труда с разных сторон, выделял наиболее проблемные ее участки и предлагал определенные 
решения, но никем из них не была установлена взаимосвязь между системой охраны труда и социально-экономическим развитием.

Переход России на рыночные рельсы был болезненным во многих аспектах. Стоит сказать, что многие механизмы советского времени просто оказались неэффрективными в рыночной экономике. Проблемным местом стала и исследуемая нами система охраны труда.

С.Г. Брусенцов отмечал, что «во времена “застойного периода" новейшей истории развития нашего государства на многих отечественных предприятиях охране труда уделялось недостаточно внимания. В советскую эпоху к этому вопросу относились достаточно формально. Во времена бурного и слабо управляемого становления рыночных отношений, в период пресловутой "горбачевской перестройки" главной своей целью руководители предприятий считали достижение максимальной прибыли в короткие сроки, при этом грубо пренебрегали правилами соблюдения элементарных норм техники безопасности или в лучшем случае отодвигали их далеко на задний план» [4]. Стоит согласиться с мнением С.Г. Брусенцова, так как советский менталитет многих руководителей действующих предприятий и сегодня не позволяет им уделять должного внимания вопросам охраны труда. Конечно, административные подразделения на предприятиях состоят не только из консервативно настроенных руководителей, и новоиспеченные управленцы все же не упускают из вида вопросы охраны труда сотрудников при параллельном решении производственных задач.

Для определения места и роли системы охраны труда в современной экономике Российской Федерации необходимо обратить внимание на уровень государственного участия в процессе ее формирования, поддержания и развития.

Так, согласно Конституции РФ, а именно ст. 37, каждый гражданин имеет право на труд в условиях, которые отвечают требованиям безопасности и гигиены. Необходимо отметить, что в Конституции РФ регламентируется также обязанность государства охранять здоровье граждан в процессе реализации их права на труд.

Трудовой кодекс Российской Федерации (ТК РФ) фриксирует следующее определение исследуемого понятия: «Охрана труда - система сохранения жизни и здоровья работников в процессе трудовой деятельности, включая правовые, социально-экономические, организационнотехнические, санитарно-гигиенические, лечебно-профрилактические, реабилитационные и иные мероприятия» [5].

Государство путем принятия соответствующих законов и нормативно-правовых актов закрепляет за собой обязанность по сохранению здоровья граждан во время осуществления ими трудовой деятельности, что выражается в регламентации норм и правил организации охраны труда и выдаче работодателям рекомендаций и предписаний по их соблюдению.

Таким образом, работодатель несет ответственность за сохранение жизни и здоровья своих работников и обеспечивает безопасность трудового процесса с помощью различных мероприятий, предусмотренных российским законодательством.

Приоритетное место институте охраны труда отводится работнику, так как в современных условиях человеческий капитал имеет высокую ценность. Общеизвестно, что организация безопасного рабочего процесса, а также развитие профессионального потенциала работников позволяют дать толчок для роста и постоянного развития хозяйствующего субъекта.

Г.Н. Тугускина в своей статье пишет: «Социально-экономическое развитие во второй половине прошлого века и начале нынешнего характеризуется возрастающей ролью человеческого фактора. В экономике современного мира человеческий капитал играет определяющую роль в достижении конкурентных преимуществ и обеспечении качественных параметров экономического роста. Перспективы этого развития в XXI в. связываются именно с человеческими ресурсами как носителями знания» [6].

На сегодняшний день развитию человеческого капитала уделяется особое внимание на разных уровнях. В соответствии с современными тенденциями предприятия должны организовывать свою работу так, чтобы имеющийся человеческий капитал не только сохранялся, но и приумножался. Достижение этого условия возможно путем грамотной организации системы охраны труда. Именно сохранение и приумножение знаний, умений и навыков трудовых ресурсов является демонстрацией социального значения труда.

Важность охраны труда в современных условиях обусловливает улучшение условий трудовой деятельности, повышение профессионализма и обеспечение безопасности труда. Такие действия свою очередь приводят к повышению благосостояния населения, увеличению продолжительности жизни, росту производительности и экономических показателей предприятия, региона и страны в целом.

С.Г. Брусенцов отмечает, что «самой высокой ценностью всегда является человек, его жизнь и здоровье. Ни размер заработной платы, ни уровень рентабельности предприятия, ни ценность производимого продукта не могут служить основанием для пренебрежения правилами 
безопасности и оправданием существующих угроз жизни или здоровью работников. Кроме того, в данном случае речь также идет о ценности конкретного человека как сотрудника с присущими ему знаниями, навыками и опытом» [7].

Стоит также отметить, что сама по себе система охраны труда позволяет решить ряд важнейших задач, которые стоят перед руководством компании. Во-первых, улучшается дисциплина на рабочих местах, что в свою очередь влияет на повышение производительности предприятия. Во-вторых, правильно организованная система нематериального стимулирования в рамках охраны труда демонстрирует персоналу заинтересованность руководства в исключении несчастных случаев и ситуаций причинения вреда здоровью работников, что позволяет избежать недобросовестного отношения к трудовому процессу среди сотрудников, а также свести к минимуму вероятность краж и текучки кадров. В-третьих, при рационально организованной системе охраны труда улучшается состояние микроклимата предприятия, что заметно сказывается не только на возрастающем качестве и эфрфективности работы, но и на имидже предприятия в целом.

Становление системы охраны труда - затратный и длительный процесс ввиду низкого реального уровня обеспечения техники безопасности на российских предприятиях, а также нестабильной экономической обстановки во внешней среде. Обеспечение охраны труда путем лишь соблюдения законодательства в данной сфере, безусловно, малопродуктивно. Ощутимого социально-экономического эффректа от системы охраны труда возможно добиться в результате сохранения масштабности проводимых мероприятий в рамках промышленной группы, концерна или кластера.

По словам Л. В. Серегиной, «одним из актуальных направлений обеспечения профессиональной безопасности и здоровья работающих является создание благоприятной производственной среды. В настоящее время в большинстве государств с развитой рыночной экономикой осуществляется поиск современных нормативных решений по таким направлениям, как фризиология и психология производственной среды» [8].

К сожалению, современные предприятия зачастую пренебрегают развитием системы охраны труда как одной из экосистем предприятия, считая ее нерентабельной и дорогостоящей.

Традиционно лидирующие позиции по частоте несчастных случаев, фактов травматизма занимают строительная, обрабатывающая, добывающая и транспортная отрасли промышленности. По данным Министерства труда России за 2018 год, количество несчастных случаев на производстве снизилось на 3 \% по сравнению с 2017 годом, а количество погибших уменьшилось на 2 \% за аналогичный период. Несмотря на это, критерий травмоопасности остается ключевым в системе охраны труда работников, так как крупные промышленные предприятия зачастую осуществляют свою деятельность с помощью устаревших производственных фондов.

Данный фракт находит подтверждение в работе Д.В. Андреева, Н.И. Лукачевского, которые констатируют, что «для России актуальность данной проблемы объясняется тем, что более чем 80 \% основополагающих фондов производств выработали свои ресурсы. Очевидно, что работа на изношенном оборудовании увеличивает вероятность возникновения аварийных ситуаций. Исходя из этого, роль вопроса организации охраны труда возрастает и занимает место среди первоочередных задач на производстве» [9].

При построении системы охраны труда для достижения оптимального социального результата необходимо обратить внимание на следующие условия:

1. Рост производительности труда за счет увеличения рабочего времени. Причем имеется в виду не продление рабочего дня конкретного работника, а сокращение простоев между сменами на промышленных предприятиях. Рационализация рабочего времени и правильная организация рабочего места позволят снизить утомляемость сотрудников и обеспечить эффрективность их деятельности. Следствием этого станет снижение травм, которые преимущественно возникают из-за спешки и невнимательности уставших работников.

2. Повышение профессионального потенциала трудового персонала в результате улучшения условий труда. Обстановка на рабочем месте и психологический настрой в коллективе оказывают прямое воздействие на состояние здоровья трудового персонала, а также косвенно способствуют увеличению средней продолжительности жизни людей. Кроме того, рост профессионального потенциала трудового коллектива можно обеспечить введением практики наставничества внутри предприятия, что будет способствовать сохранению знаний и передаче их новым трудовым ресурсам. В ряде случаев к наставничеству могут быть привлечены пенсионеры и ветераны производства, имеющие богатый профессиональный опыт.

3. Увеличение совокупного национального продукта, который является одним из показателей социально-экономического развития.

В.И. Коробко считал, что «условия труда зависят от определенного соединения производственных факторов, которое со своей стороны оказывает влияние на производительность и результативность труда, на состояние здоровья работающих» [10]. 
Рассмотрев социальные аспекты охраны труда, представляется возможным раскрыть ее экономическое значение. Эффрективность, полученная от проведенных мероприятий по обеспечению безопасности труда, улучшению условий и режима труда, оказывает непосредственное влияние на показатели экономического развития предприятия. Иными словами, экономическая эффективность есть не что иное, как проявление результатов развития системы охраны труда организации. К таким результатам можно отнести:

- повышение производительности;

- минимизацию потерь производства;

- увеличение фонда рабочего времени;

- снижение текучести кадров.

Экономическое и социальное значение системы охраны труда взаимообусловлены.

Как отмечает С.О. Кузьмина, «охрану труда следует рассматривать как единую категорию, являющуюся сложной, многоаспектной системой, заключающей в себе специфические цели, задачи и средства их достижения. Целью общества является создание благоприятных условий трудовой деятельности и охрана труда работников. Условия и охрана труда в совокупности обеспечивают безопасность и сохранение здоровья, а также работоспособность человека в процессе труда. Важной предпосылкой создания благоприятных условий труда является объективная оценка их настоящего уровня» [11].

Е. А. Краснощекова, проанализировав состояние систем охраны труда в государствах с развитой рыночной экономикой, пришла к выводу о том, что в нашей стране, в отличие от других стран, практически не используют оценку профессиональных рисков, а наибольшее распространение получила аттестация рабочих мест по условиям труда [12].

В современных производственных условиях охрана труда действительно приобрела важное значение в связи с интенсивным развитием цифрового пространства, а также в связи с созданием принципиально новых промышленных структур. Предприятия на данный момент используют актуальные механизмы в управлении организационной средой, а также инновационные подходы к производству, что делает охрану труда высоко востребованной.

На сегодняшний день одной из основных задач любого предприятия является создание такой системы охраны труда, при которой будет обеспечиваться безопасность трудовых ресурсов. Это объясняется тем, что ощущение защищенности и комфорта в трудовом процессе обусловливает высокую производительность, низкие потери и благоприятную атмосферу в трудовом коллективе.

Система охраны труда является ключевой позицией в социально-экономическом развитии предприятия. Доказательством данного тезиса служат выявленные социальные и экономические ее параметры, без которых трудно представить себе развитие и эффективность организации. Сама по себе система является неким условием, без которого не произойдет социально-экономического развития производственной структуры, прежде всего это касается обеспечения безопасности работников.

Система охраны труда на предприятии призвана обеспечить безопасность жизни и здоровья его работников с целью сохранения и преумножения трудового потенциала производства, выраженного в человеческом капитале. Только трудоспособный коллектив способен добиться экономического роста предприятия и этим поддержать социально-экономическое развитие. Таким образом, получается, что человеческий капитал является связующим звеном между социально-экономическим развитием и системой охраны труда. Данную взаимосвязь можно представить в виде схемы для более четкого представления роли и места системы (см. рис. 1).

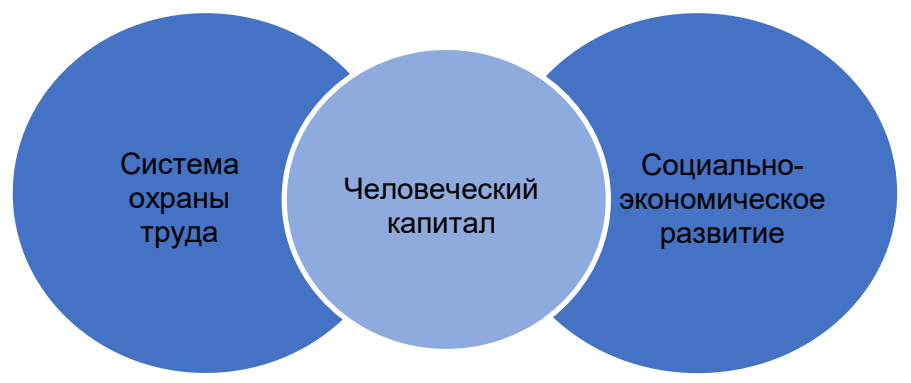

Рисунок 1 - Взаимосвязь системы охраны труда и социально-экономического развития 
Охрана труда в РФ представляет собой сложный институт, объединяющий нормы ряда отраслей права. Преимущественно он регулируется положениями трудового права.

По нашему мнению, для достижения социальной значимости охраны труда в современных условиях стоит обратить внимание на улучшение условий трудовой деятельности, повышение профессионализма работников, обеспечение безопасности рабочего процесса, что в свою очередь приведет к повышению благосостояния населения, увеличению продолжительности жизни, росту производительности предприятия и улучшению экономических показателей предприятия, региона и страны в целом.

В ходе проведённого исследования было выявлено, что именно ценность человека и его безопасность являются определяющими параметрами системы охраны труда. Это база, на которой строится взаимодействие руководства и трудовых ресурсов предприятия для достижения оптимальных результатов социально-экономической направленности.

Новизна и принципиальное отличие данного исследования от других состоит в том, что нами была выявлена взаимосвязь между системой охраны труда и социально-экономическим развитием через обязательный элемент того и другого - человеческий капитал. Это стало возможно в результате обобщения итогов имеющихся исследований по данной проблеме и изучения социальных и экономических аспектов системы охраны труда, реализуемой на практике в организациях производственного кластера экономики России.

Мы считаем, что система охраны труда позволяет обеспечить сохранение и приумножение человеческого капитала, что в свою очередь способствует достижению социально-экономического роста.

К результатам проведённого исследования стоит отнести определение связующего элемента - человеческого капитала - между системой охраны труда и социально-экономическим развитием. Выявленная взаимосвязь позволяет принять человеческий капитал как обязательный элемент системы охраны труда, оказывающий влияние на социально-экономическое развитие.

Становление системы охраны труда сопряжено с немалыми финансовыми затратами и может потребовать значительных временных ресурсов. В связи с этим целесообразно детально проработать методику реализации системы охраны труда на предприятиях в рамках нестабильной экономической ситуации, а также произвести оценку данной системы с точки зрения ее социально-экономической эфффективности.

\section{Ссылки:}

1. Брусенцов С.Г. Роль охраны труда на производстве [Электронный ресурс] // Концепт. 2015. № 12 (декабрь). С. 81-85. URL: http://e-koncept.ru/2015/15423.htm (дата обращения: 16.07.2019).

2. Тугускина Г.Н. Человеческий капитал: управление развитием [Электронный ресурс] // Известия высших учебных заведений. Поволжский регион. Экономические науки. 2016. № 1 (4). С. 51-58. URL: https://izvuz_econ.pnzgu.ru/files/izvuz_econ.pnzgu.ru/06(4).pdf (дата об-ращения: 15.07.2019).

3. Косинова Н.В., Комаров О.К. Аспекты развития охраны труда в учреждениях образования [Электронный ресурс] // OHB. 2015. № 2 (136). C. 232-234. URL: https://ru.booksc.xyz/book/50476263/a0694а (дата обращения: 31.08.2019) ; Кузьмина С.О. Охрана труда на предприятии [Электронный ресурс] // Молодой ученый. 2018. № 21. С. 259-262. URL: https://moluch.ru/archive/207/50601/ (дата обращения: 01.09.2019).

4. Брусенцов С.Г. Указ соч.

5. Трудовой кодекс Российской Федерации. М., 2011. 192 с.

6. Тугускина Г.Н. Указ соч.

7. Брусенцов С.Г. Указ соч.

8. Серегина Л.В. Концептуальные подходы к охране труда в Российской Федерации [Электронный ресурс] // Журнал российского права. 2015. № 11 (227). С. 95-106. https://doi.org/10.12737/14375.

9. Андреев Д.В., Лукачевский Н.И. Охрана труда на производстве // Московский экономический журнал. 2018 . № 5 (1). С. 320-326. https:// doi.org/10.24411/2413-046X-2018-15028.

10. Коробко В.И. Охрана труда : учебное пособие. М., 2012. 239 с.

11. Кузьмина С.О. Указ соч.

12. Краснощёкова Е.А. Состояния и актуальные задачи в области охраны труда на российских предприятиях // Вестник Поволжской академии государственной службы. 2011. № 1 (26). С. 196-200.

Редактор: Ситникова Ольга Валериевна Переводчик: Бирюкова Полина Сергеевна 